\title{
LUZ ULTRAVIOLETA NA INIBIÇÃO DO CRESCIMENTO DE LEVEDURAS
}

Recebido: $14 / 12 / 2016$

Aceito: $27 / 05 / 2017$

\author{
SILVA, Anna Luiza'; \\ SERRA, Emanoele Figueiredo"; \\ RIPOLL, Márcia Kutscher'; \\ WALLER, Stefanie Bressan"; \\ OSÓRIO, Luiza da Gama'; \\ GOMES, Angelita dos Reis'; \\ FARIA, Renata Osório de"; \\ MEIRELES, Mário Carlos Araújo'.
}

\footnotetext{
${ }^{1}$ Centro de Diagnóstico e Pesquisa em Micologia Veterinária, Departamento de Veterinária Preventiva, Faculdade de Veterinária, Universidade Federal de Pelotas.
}

\section{RESUMO}

luz ultravioleta (UV) possui ação germicida, sendo amplamente utilizada na
descontaminação de superfícies e materiais em laboratório. Essa radiação provoca
alterações fotobioquímicas que promovem a inviabilidade ou morte dos microorganismos atingidos. As leveduras são células eucariotas, sendo assim, possuem núcleo que protege o seu material genético, necessitando de uma maior exposição à UV quando comparadas às células procariotas. O objetivo deste trabalho foi avaliar a eficiência da radiação ultravioleta sobre as leveduras expostas em cabine de segurança biológica. No estudo foram utilizados um isolado de Cryptoccocus gattii, um de Rhodotorula sp. e uma cepa padrão de Candida albicans (ATCC 14053). Utilizou-se a Norma M27-A2 do NCCLS para a preparação dos inóculos, diluindo-os nas concentrações 1, 5 e 10 da escala McFarland. Cada inóculo foi semeado em seis placas de Potato Dextrose Agar (PDA). Após, metade das placas foi exposta à radiação ultravioleta por 15 minutos em cabine de segurança biológica. Todas as placas foram incubadas em estufa a $37{ }^{\circ} \mathrm{C}$ por 10 dias. As placas semeadas com $C$. albicans e $C$. gattii e expostas à UV tiveram seu crescimento inibido. As placas semeadas com Rhodotorula sp. e expostas à radiação UV tiveram crescimento, porém com uma diminuição nas unidades formadoras de colônias (UFC) quando comparadas com as não expostas. Nas condições deste trabalho, comprovou-se a eficácia desse método de descontaminação em relação a $C$. albicans e $C$. gattii, assim como a necessidade de maiores pesquisas da atuação da UV diante do gênero Rhodotorula.

Palavras-chave: Descontaminação. Desinfecção. Fungos. Fungicida. UV. 


\section{INTRODUÇÃO}

Fungos são seres ubíquos que se destacam por crescerem e se propagarem pela poeira ambiental, por isso, dificilmente um ambiente está livre da contaminação fúngica, fato que ocorre também em laboratórios e seus equipamentos (ANVISA, 2010; NOBRE; CLEFF, 2009). Dessa forma, deve-se destacar a importância da desinfecção, pois esta resulta na redução da carga microbiana (ANVISA, 2010; MATTEI et al., 2014).

As instalações, equipamentos e procedimentos de um laboratório de micologia devem estar de acordo com as normas de biossegurança vigentes no país, visto que a correta aplicação desses regimentos contribui para a proteção das amostras processadas em relação a contaminantes externos, da equipe que manuseia e do meio ambiente (BRASIL, 2006; SANGIONI, 2012; UEKI et al., 2006).

As cabines de segurança biológicas (CSB) são consideradas o principal equipamento de contenção de micro-organismos nos laboratórios, sendo capazes de proporcionar a diminuição de aerossóis e borrifos gerados nos procedimentos realizados dentro delas (BRASIL, 2006). Dependendo das características de construção e aplicações, as CSB são classificadas em classe I, II e III, e a escolha para utilização dependerá dos riscos e dos agentes biológicos a serem manipulados (UEKI et al., 2008). Todas as CSB devem possuir em seu interior uma lâmpada ultravioleta (UV) e, segundo normas de biossegurança, após utilização da CSB, a luz UV precisa permanecer ligada durante 15 minutos para a descontaminação (BRASIL, 2006; SANGIONI, 2012).

A radiação ultravioleta é um processo físico de esterilização frequentemente utilizado em laboratórios (PIGATTO, 2008). Esse processo corresponde às ondas eletromagnéticas com comprimento na faixa de 200 a 400 nanômetros $(\mathrm{nm})$, em que o comprimento de onda de $254 \mathrm{~nm}$ possui atividade germicida mais efetiva (RIBEIRO et al., 2004). Estudos evidenciam que ela é letal para bactérias, esporos, vírus, fungos e algas (UEKI et al., 2008), mostrando-se uma forma eficiente e ambientalmente segura na desinfecção de sólidos e líquidos (ROCHA et al., 2011).

Ao contato com os micro-organismos, a UV provoca alterações fotobioquímicas que modificam o DNA ou RNA celular e de organelas intracelulares, promovendo a inviabilidade 
ou a morte (LENZI, 2005). As leveduras são células eucariotas e por possuírem núcleo necessitam de uma maior exposição a essa radiação quando comparadas às células procariotas. Desta forma, o uso de células fúngicas torna-se uma opção viável para a avaliação da UV como método de desinfecção (LOBO et al., 2009; TORTORA et al., 2005).

Devido as particularidades estruturais das células leveduriformes e a importância da desinfeção em ambientes laboratoriais, o estudo proposto visou analisar o efeito da radiação ultravioleta sobre o crescimento das leveduras expostas em CSB e sua eficiência como esterilizante em laboratórios.

\section{MATERIAL E MÉTODOS}

No experimento foram utilizados isolados de Cryptococcus gattii, Rhodotorula sp. e uma cepa padrão de Candida albicans (ATCC 14053), todos provenientes da micoteca do Centro de Diagnóstico e Pesquisa em Micologia Veterinária (MicVet) pertencente a Faculdade de Veterinária da Universidade Federal de Pelotas - UFPEL.

A metodologia foi estabelecida através da Norma M27-A2 do NCCLS. Para a preparação do inóculo, as leveduras foram repicadas por esgotamento em placa de Petri contendo meio de cultura Potato Dextrose Agar (PDA) e acondicionadas em estufa a $37^{\circ} \mathrm{C}$ por 48 horas.

Após, suspendeu-se a colônia obtida nas placas em um tubo de ensaio contendo solução salina tamponada (PBS) acrescida com uma gota de Tween 20. As soluções foram homogeneizadas em agitador de tubos durante 15 segundos, e o inóculo das três leveduras foram ajustados às concentrações de 1, 5 e 10 de acordo com escala de McFarland.

Posteriormente, em triplicata, inoculou-se $10 \mu \mathrm{L}$ de cada solução em placas de Petri de plástico contendo PDA e em seguida foram espalhados pelo método de surface plate. Metade das placas semeadas foram destampadas e expostas à radiação ultravioleta em uma câmara de segurança biológica (BioFlux II A/Filtracom) por 15 minutos com o fluxo laminar ligado.

Para o controle negativo, três placas foram semeadas com o PBS sem exposição à luz UV. Ao final, todas as placas foram incubadas em estufa a $37^{\circ} \mathrm{C}$ por dez dias com avaliação diária do crescimento fúngico. 
Para realização do estudo foi utilizada uma lâmpada nova de ultravioleta de baixa pressão de vapor de mercúrio com potência nominal de $30 \mathrm{~W}$ (Phillips ${ }^{\circledR}$ ), localizada na parte superior da câmara de fluxo laminar com uma altura de $45 \mathrm{~cm}$ das placas.

\section{RESULTADOS E DISCUSSÃO}

Os fungos leveduriformes comumente possuem crescimento entre 24 a 48 h após incubação em estufa com temperatura em torno de $37{ }^{\circ} \mathrm{C}$ (MEIRELES; NASCENTE, 2009). Neste experimento, optou-se por avaliar as placas até o décimo dia de incubação, para assim garantir a ausência de crescimento tardio dos micro-organismos.

O gênero Candida é composto por centenas de espécies, com destaque para a C. albicans, que é a mais frequentemente envolvida com patologias nos homens e animais domésticos. Suas colônias são de coloração branca a creme, com textura cremosa e podem ser lisas ou rugosas. Na microscopia notam-se células arredondadas, sem a presença de cápsula, podendo apresentar pseudo-hifas (CRUZ, 2010).

A infecção por Candida spp. pode ser facilitada por vários processos patológicos, fisiológicos ou traumáticos, sendo a imunossupressão o mais comum. Dessa forma, a candidíase é considerada uma micose oportunista, sendo o quarto patógeno mais isolado de hemoculturas nos hospitais brasileiros (COLOMBO et al., 2006; MALUCHE; SANTOS, 2008).

Neste estudo, as placas semeadas com Candida albicans e expostas na CSB com radiação UV por 15 min, tiveram seu crescimento inibido até o último dia de incubação (Figura 1), em todas as concentrações testadas. Resultado semelhante ao de Vargas (2011), que observou que após $60 \mathrm{~s}$ de exposição à radiação UV, houve uma redução decimal de C. albicans. Vargas (2011) descreve a C. albicans como mais resistente à radiação UV, em comparação a Saccharomyces boulardii, uma vez que a segunda levedura necessitou apenas de $40 \mathrm{~s}$ de exposição para sua redução decimal. Embora exista a descrição dessa maior resistência à ação UV, a C. albicans no estudo atual foi inibida. 


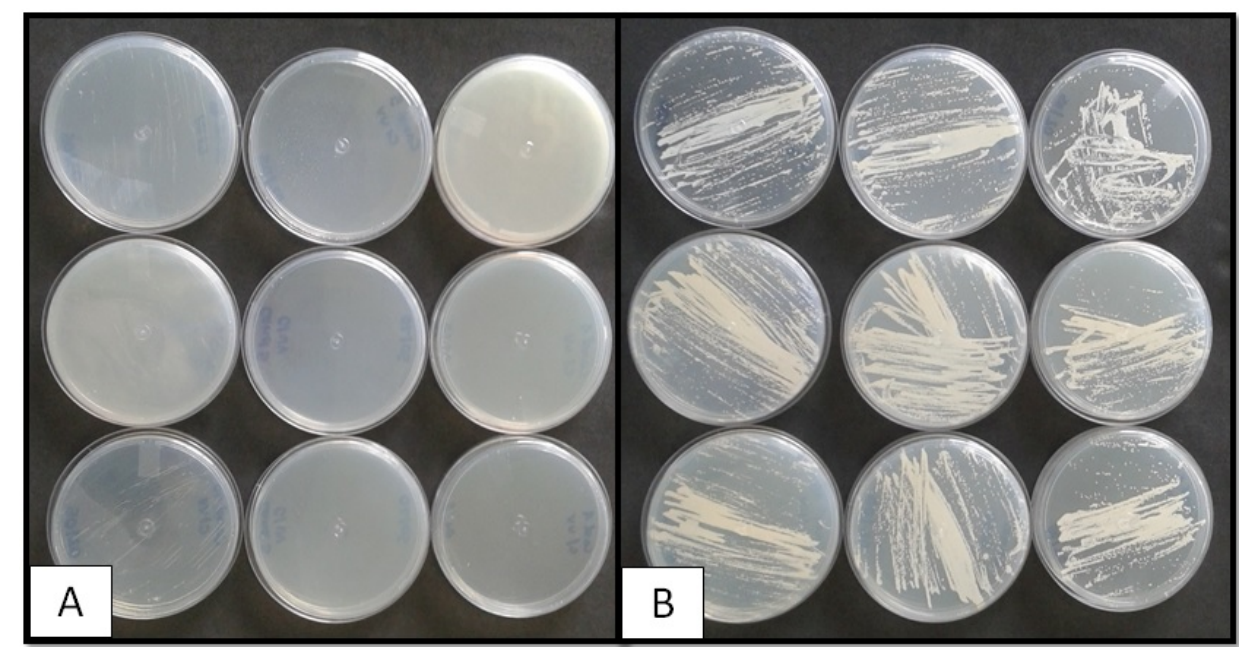

Figura 1 - Placas semeadas com Candida albicans em três concentrações, após dez dias de incubação. A) Placas expostas 15 minutos na radiação UV. B) Placas não expostas à radiação UV.

As colônias do gênero Cryptococcus são de coloração creme, lisas e mucoides e, quando semeadas em ágar inclinado, o fungo escorre pela superfície do meio e se deposita no fundo (CRUZ, 2010). Na microscopia observam-se células globosas com ou sem brotamento e envolvidas por cápsula de polissacarídeo (FARIA; XAVIER, 2009). As placas semeadas com Cryptococcus gattii neste estudo, assim como as semeadas com C. albicans, tiveram o crescimento inibido até o último dia de incubação após exposição à radiação UV (Figura 2).

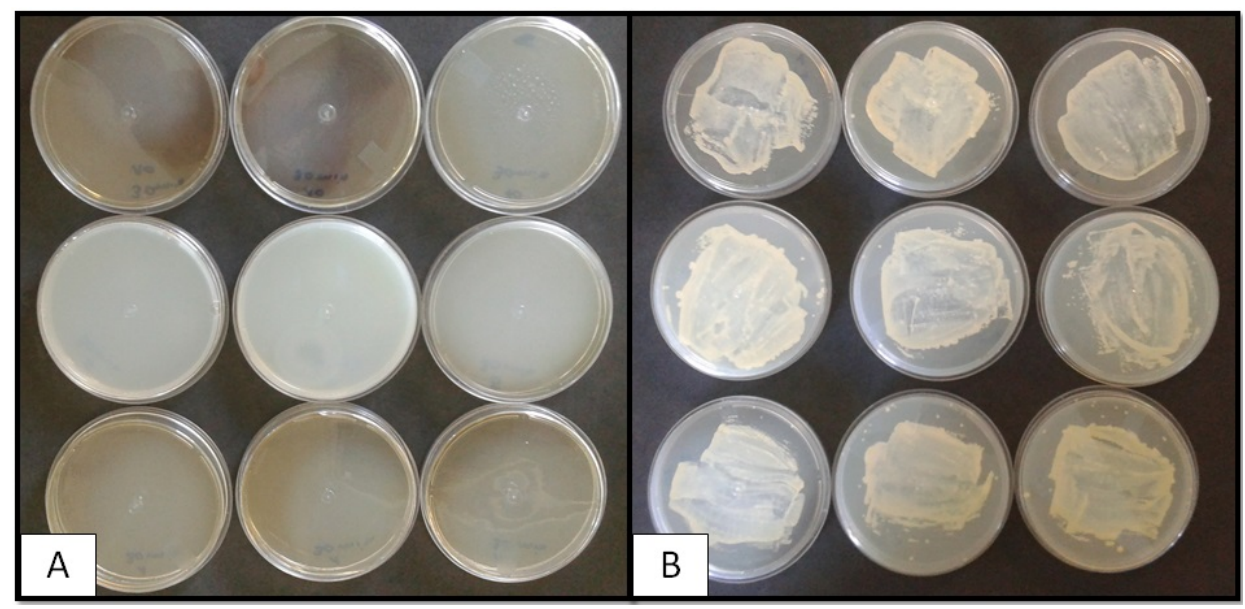

Figura 2 - Placas semeadas com Cryptococcus gattii em três concentrações, após dez dias de incubação. A) Placas expostas 15 minutos na radiação UV. B) Placas não expostas à radiação UV.

As colônias do gênero Rhodotorula são de coloração alaranjada a avermelhada, com aspecto mucoide devido à presença de cápsula, podendo se apresentar também como pastosas e 
rugosas (SIDRIM; ROCHA, 2004). Essas leveduras são consideradas saprófitas e contaminantes comuns de amostras.

Um estudo realizado em 2015 comprovou a presença de leveduras do gênero Rhodotorula em ambientes hospitalares, obtendo-se isolamento do fungo em $20,7 \%$ das amostras coletadas (GONÇALVES et al., 2015). Além disso, há muitos relatos que citam esse microorganismo como um patógeno oportunista emergente, principalmente em pacientes imunocomprometidos (GOMEZ-LOPEZ et al., 2005). Consequentemente, percebe-se a importância de estudos que descrevam formas de desinfecção diante de Rhodotorula spp. (GONÇALVES et al., 2015).

Nas placas semeadas com Rhodotorula sp. e expostas à luz UV por 15 min, não houve inibição em nenhuma das concentrações testadas (Figura 3), porém houve uma diminuição das unidades formadoras de colônias (UFC) quando comparadas com as placas não expostas à UV. Esses resultados corroboram com os encontrados por Santiago (2015), que testou leveduras extremófilas quanto à capacidade de resistir à radiação ultravioleta. Um estudo demonstrou que espécies de Rhodotorula conseguem resistir a intensidades maiores que $900 \mathrm{~J} / \mathrm{m}^{2}$ de radiação UV, devido ao fato dessas leveduras produzirem carotenóides, um pigmento fotoprotetor capaz de absorver a radiação UV em comprimentos de onda diferentes (WYNN-WILLIAMS; EDWARDS, 2002). Porém sugere-se maiores estudos sobre o comportamento da Rhodotorula spp. quando submetida à radiação UV.

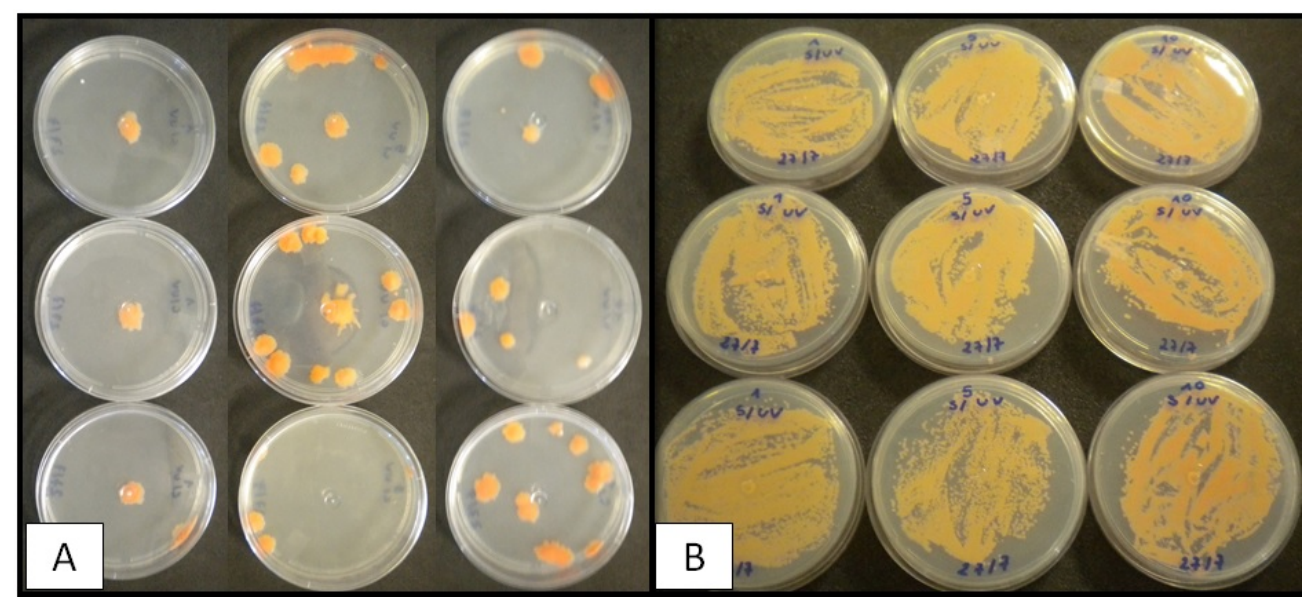

Figura 3 - Placas semeadas com Rhodotorula sp. em três concentrações, após dez dias de incubação. A) Placas expostas 15 minutos na radiação UV. B) Placas não expostas à radiação UV. 
No controle negativo, placas semeadas com PBS e não expostas à UV, não houve crescimento de micro-organismos. Certificando assim, a inocuidade dos materiais utilizados para a realização do experimento, bem como do ambiente ao qual foram expostos (CSB).

Ueki et al. (2006) realizaram um estudo semelhante, no qual testaram a ação germicida da radiação ultravioleta diante de micobactérias. Todas as placas que tiveram exposição direta à UV durante cinco minutos, apresentaram inibição do crescimento das bactérias. Os autores sugerem que esses resultados demonstram que a UV garante a descontaminação adequada das CSB e de materiais. As micobactérias precisaram apenas de cinco minutos de exposição à luz UV para serem inibidas, sendo descritas como mais sensíveis à radiação UV quando comparadas às células fúngicas. Isso ocorre, pois, além das leveduras terem o DNA protegido por membrana, as células são maiores e possuem uma parede celular espessa e muito resistente, composta de oligossacarídeos (LOBO et al., 2009; TORTORA et al., 2005).

Com as condições estabelecidas neste trabalho, salienta-se a eficácia da luz UV diante de Candida albicans e Cryptococcus gattii e a importância de maiores estudos da ação germicida da UV em relação ao gênero Rhodotorula.

Percebe-se também, que a prática laboratorial de utilizar $15 \mathrm{~min}$ de luz UV antes da manipulação em CSB é eficiente, porém existem limitações. Primeiro, deve-se estar ciente que a radiação UV é um método secundário, necessitando junto a ela empregar as boas práticas e descontaminação química, como hipoclorito de sódio ou álcool etílico (SANGIONI, 2012; UEKI et al., 2008). Também deve-se ressaltar que a luz UV não penetra em materiais, agindo apenas na superfície e que seu potencial é afetado pelo acúmulo de sujidades e pela distância do plano a ser desinfetado. Sendo assim, é importante adotar os cuidados devidos para alcançar melhores resultados de desinfecção (UEKI et al., 2008).

\section{CONCLUSÃO}

Nas condições deste experimento, a ação germicida da luz UV sobre a Candida albicans e o Cryptococcus gattii foi efetiva. Entretanto, nas placas semeadas com Rhodotorula sp. não houve a inibição total em nenhuma concentração testada, mostrando a necessidade de maiores estudos da ação UV diante desse gênero. 


\section{ULTRAVIOLET LIGHT IN THE INHIBITION OF YEAST GROWTH}

\section{ABSTRACT}

$\mathrm{T}$ he ultraviolet light (UV) has germicide action, therefore it is widely utilized as a decontamination method to surfaces and laboratory supplies. This radiation causes photobiochemical changes that promote microorganisms' unavailability or death. The yeasts are eukaryotic cells, which have a nucleus that protect their genetic material, being one of the reasons why they need a higher UV light exposition when compared to prokaryotic cells. The goal of this paper was to evaluate the efficiency of the exposure to ultraviolet radiation on the yeast growth in biological safety cabinet. In this study was used an isolated strain of Cryptoccocus gattii, one of Rhodotorula sp. and a pattern strain of Candida albicans (ATCC 14053). Standard M27-A2 of the NCCLS was used to prepare the inoculum in the concentrations 1, 5 and 10 of the McFarland scale. Each inoculum was sown in six Petri dish with Potato Dextrose Agar (PDA). After that, half of they were exposed to the ultraviolet radiation for 15 minutes in the biological safety cabinet. All the Petri dishes were incubated at $37{ }^{\circ} \mathrm{C}$ for 10 days. The plates sown with C. albicans and C. gattii that were exposed to UV had their growth inhibited. The plates sown with Rhodotorula sp. and exposed to UV radiation had growth, however, they had less colony-forming units when compared to the non-exposed ones. In these work conditions, it was proved the efficacy of this method of decontamination of $C$. albicans and $C$. gattii. Also, the need for further studies about on the action of UV radiation in front to Rhodotorula spp. is evident.

Keywords: Decontamination. Disinfection. Fungi. Fungicide. UV.

\section{LUZ ULTRAVIOLETA EN LA INHIBICIÓN DEL CRECIMIENTO DE LEVADURAS}

\section{RESUMEN}

a luz ultravioleta (UV) tiene acción germicida, siendo ampliamente utilizada en la descontaminación de superficies y materiales en laboratorio. Esta radiación provoca cambios foto-bioquímicos que promueven la inviabilidad o muerte de los microorganismos afectados. Las levaduras son células eucariotas, poseen núcleo que protege su material genético, siendo uno de los motivos por la cual necesitan una mayor exposición a la UV cuando se compara con las células procariotas. El objetivo de este trabajo fue evaluar la eficiencia de la radiación ultravioleta sobre las levaduras expuestas en cabina de seguridad biológica. En el estudio se utilizó un aislado de Cryptoccocus gattii, uno de Rhodotorula sp. y una cepa estándar de Candida albicans (ATCC 14053). Se utilizó la Norma M27-A2 del NCCLS para la preparación de los inóculos, diluyéndolos en las concentraciones 1, 5 y 10 de la escala McFarland. Cada inoculo fue sembrado en seis placas de Potato Dextrosa Agar (PDA). Después, la mitad de las placas fue expuesta a la radiación ultravioleta durante 15 minutos, en cabina de seguridad biológica. Todas las placas se incubaron a $37^{\circ} \mathrm{C}$ 
durante 10 días. Las placas sembradas con C. albicans y C. gattii y expuestas a la UV tuvieron su crecimiento inhibido. Las placas sembradas con Rhodotorula sp. y expuestas a la radiación UV tuvieron crecimiento, pero con una disminución en las unidades formadoras de colonias (UFC) en comparación con las no expuestas. En las condiciones de este trabajo, se comprobó la eficacia de este método de descontaminación en relación a $C$. albicans y $C$. gattii, así como la necesidad de mayores investigaciones sobre la actuación de la UV frente al género Rhodotorula.

Palabras clave: Descontaminación. Desinfección. Hongos. Fungicida. UV.

\section{AGRADECIMENTOS}

Os autores agradecem a Coordenação de Aperfeiçoamento de Pessoal de Nível Superior (CAPES), ao Conselho Nacional de Desenvolvimento Científico e Tecnológico (CNPq), e a Fundação de Amparo à Pesquisa do Estado do Rio Grande do Sul (FAPERGS) pelo auxílio financeiro.

\section{REFERÊNCIAS}

ANVISA - AGÊNCIA NACIONAL DE VIGILÂNCIA SANITÁRIA. Segurança do paciente em serviços de saúde: Limpeza e desinfecção de superfície. Brasília: Anvisa, 2010. 116p.

BRASIL. Biossegurança em laboratórios biomédicos e de microbiologia. Ministério da Saúde. Secretaria de Vigilância em Saúde. Departamento de Vigilância Epidemiológica. 3a ed. Brasília: Ministério da Saúde, 2006. 290p.

COLOMBO, A. L.; NUCCI, M.; PARK, B. J.; et al. Epidemiology of Candidemia in Brazil: a Nationwide Sentinel Surveillance of Candidemia in Eleven Medical Centers. Journal of Clinical Microbiology, v. 44, p. 2816-2823, 2006.

CRUZ, L. C. H. da. Micologia veterinária. 2. ed. Rio de Janeiro: Revinter, 2010. 348p.

FARIA, R. O.; XAVIER, M. O. Criptococose. In: MEIRELES, M. C. A.; NASCENTE, P. S. Micologia Veterinária. Pelotas: Ed. Universitária UFPEL, 2009. Cap. 5, p. 191-203.

GOMEZ-LOPEZ, A.; MELLADO, E.; RODRIGUEZ-TUDELA, J; et al. Susceptibility profile of 29 clinical isolates of Rhodotorula spp. and literature review. Journal of Antimicrobial Chemotherapy, v. 55, p. 312-316, 2005. 
GONÇALVES, C. L.; MOTA, F. V.; MENDES, J. F.; et al. Leveduras isoladas em unidade de terapia intensiva do sul do Rio Grande do Sul, Brasil. Revista de Epidemiologia e Controle de Infecção, v. 5, n. 2, p. 111-112, 2015.

LENZI, C. F. Estudos de complementação fenotípica de mutante pso 2-1 de Saccharomyces cerevisiae pelos genes uvr de Escherichia coli. Porto Alegre: UFRGS, 2005. 85p. Dissertação (Mestrado). Programa de Pós-Graduação em Biologia Celular e Molecular, Centro de Biotecnologia do Estado do Rio Grande do Sul, Universidade Federal do Rio Grande do Sul, 2005.

LOBO, M. G.; COSTA, B. P.; WISBECK, E. Avaliação da desinfecção de água por reator utilizando radiação ultravioleta. Revista de Ciências Ambientais, v. 3, p. 21-36, 2009.

MALUCHE, M. E.; SANTOS, J. I. Candida sp. e infecções hospitalares: aspectos epidemiológicos e laboratoriais. Revista Brasileira de Análises Clínicas, v. 40, n. 1, p. 65-67, 2008.

MATTEI, A. S.; MADRID, I. M.; SANTIN, R.; et al. Presença de fungos com potencial patogênico em instrumento de tosa. Archives of Veterinary Science, v. 19, n. 2, p. 40-45, 2014.

MEIRELES, M. C. A.; NASCENTE, P. S. Micologia Veterinária. 1. ed. Pelotas: Ed. Universitária UFPEL, 2009. 456p.

NCCLS. Método de Referência para Testes de Diluição em Caldo para a Determinação da Sensibilidade a Terapia Antifúngica das Leveduras. 2. ed. NCCLS document M27-A2. Estados Unidos, 2002.

NOBRE, M. O.; CLEFF, M. B. A Célula Fúngica. In: MEIRELES, M. C. A.; NASCENTE, P. S. Micologia Veterinária. Pelotas: Ed. Universitária UFPEL, 2009. Cap. 3, p. 31-40.

PIGATTO, G. Irradiação UV em Xandomonas campestris pv. campestris visando a produção da goma xantana. São José do Rio Preto: UNESP, 2008. 77 f Dissertação (Mestrado), Instituto de Biociências, Letras e Ciências Exatas, Universidade Estadual Paulista, 2008.

RIBEIRO, R. P.; SANTOS, V. M.; MEDEIROS, E. C.; et al. Avaliação do fator de proteção solar (FPS) in vitro de produtos comerciais e em fase de desenvolvimento. Pharmacia Brasileira, $v$. 16, p. 86-88, 2004.

ROCHA, B. C. C. M.; REIS, R. P. A.; ARAÚJO, J. V. G. Avaliação de sistema de tratamento de água de chuva coletadas em telhado de cimento amianto, utilizando filtração e desinfecção por UV e cloro. Revista Eletrônica de Engenharia Civil, v. 1, n. 3, p. 12-18, 2011. 
SANGIONI, L. A.; PEREIRA, D. I. B.; VOGEL, F. S. F.; et al. Princípios de biossegurança aplicados aos laboratórios de ensino universitário de microbiologia e parasitologia. Ciência Rural, $v$. 43, n. 1, 2013.

SANTIAGO, I. F. Diversidade e bioprospecção de fungos associados a liquens presentes em ecossistemas extremos. Belo Horizonte: UFMG, 2015. 136p. Tese (Doutorado), Universidade Federal de Minas Gerais, 2015.

SIDIRM, J.; ROCHA, M. Micologia médica à luz de autores contemporâneos. Rio de Janeiro: Guanabara Koogan, 2004. 388p.

TORTORA, G. J.; FUNKE, B. R.; CASE, C. L. Microbiologia. 8. ed. Porto Alegre: Artmed, 2005. $894 p$.

UEKI, S. Y. M.; GEREMIAS, A. L.; MONIZ, L. L.; et al. Cabine de Segurança Biológica: efeito da luz ultravioleta nas micobactérias. Revista Instituto Adolfo Lutz, v. 65, n. 3, p. 222-224, 2006.

UEKI, S. Y. M.; CHIMARA, E.; YAMAUCHI, J. U.; et al. Monitoramento em cabine de segurança biológica: manipulação de cepas e descontaminação em um laboratório de micobactérias. Jornal Brasileiro de Patologia e Medicina Laboratorial, v. 44, n. 4, p. 263-269, 2008.

VARGAS, K. C. Estudos dos efeitos da radiação ultravioleta C e TFD em células de Saccharomyces boulardii e Candida albicans. Curitiba: UTPR, 2011. 77p. Dissertação (Mestrado). Programa de Pós-Graduação em Engenharia Elétrica e Informática Industrial, Universidade Tecnológica Federal do Paraná, 2011.

WYNN-WILLIAMS, D.; EDWARDS, H. M. Environmental UV Radiation: Biological Strategies for Protection and Avoidance. In: Astrobiology. Horneck, G., and

Baumstark-Khan, C. Springer Berlin Heidelberg, p. 245-260, 2002.

Autor para correspondência: Anna Luiza Silva. Universidade Federal de Pelotas, Faculdade de Veterinária, Campus Universitário, Capão do Leão (RS), CEP 96010-900, Brasil. annavet@live.com 